\title{
IMPACT OF ALCOHOL ABUSE ON ACADEMIC PERFORMANCE AMONG SENIOR SECONDARY SCHOOL STUDENTS IN JALINGO EDUCATION ZONE, TARABA STATE - NIGERIA: COUNSELLING IMPLICATIONS
}

\author{
${ }^{1}$ Adamu Nuhu Naomi (Ph.D) and ${ }^{2}$ Menchak Clifford Yubsih
}

1. Department of Guidance and Counselling, Faculty of Education, Taraba State University, Jalingo, PMB 1167, Jalingo, Taraba State, Nigeria.

2. Department of Guidance and Counselling, Faculty of Education, Taraba State University, Jalingo, PMB 1167, Jalingo, Taraba State, Nigeria.

\section{E-mail: cliffordmenchak1@gmail.com}

\begin{abstract}
This study investigated Impact of Alcohol Abuse on Academic Performance among Senior Secondary School Students in Jalingo Education Zone of Taraba state, Nigeria. The zone has three Local Government Areas namely: Ardo-Kola, Jalingo and Lau LGAs. To guide the study, one research question and one hypothesis were formulated. Descriptive survey research design was used. The population of this study comprised of all the SSII students of 2019/2020 Academic session in Jalingo Education Zone of Taraba State with total enrolment of four thousand, five hundred and Ninety-four students (4,594). Purposeful random sampling was used to collect the sample of three hundred and sixty-eight (368). Research instrument titled; Impact of Alcohol Abuse on Academic Performance among Senior Secondary School Students Questionnaire tagged [IAAAPSSSSQ] was used to collect data. The reliability of instrument was established using Cronbach-alpha method, the data collected were analysed using descriptive statistics of mean and standard deviation while inferential statistics of chisquare was used to test the hypothesis at 0.05 level of significance. The instrument was pilot tested and the mean reliability index was 0.705, the findings of the study revealed that alcohol abuse leads to poor academic performance among senior secondary school students. It is recommended that the Policy Makers of the State should develop a strong comprehensive policy that prohibits alcohol abuse especially in schools.
\end{abstract}

Keywords: Impact, Alcohol Abuse, Academic Performance, Senior Secondary School Students. 


\section{Introduction}

Academic performance is the outcome of education, the extent to which a student, teacher or institution has achieved their educational goals. Academic performance is commonly measured by examination or continuous assessment but there is no general agreement on how it is best tested or which aspects are most important. The academic performance of students is greatly affected by alcohol abuse and addiction (Attah, Baba \& Audu, 2016). Idoko, Muyiwa \& Agoha (2015) discussed that parents care about their child's academic performance because they believe that a good academic result will provide lucrative careers with adequate job security. Academic Performance in school is evaluated in a number of ways. For instance, students demonstrate their knowledge by taking written and oral continuous assessments tests or examination, performing presentations, turning in home work and participating in class activities and group discussions.

Various researches have been carried out to determine the factors contributing to students' poor academic performance. Ali, Haider, Munir, Khan \& Ahmed (2013) opined that a student's educational success is contingent heavily on social status of student's parents/ guardians in the society. Brown and Pela (2000) noticed the same that parent's income or social status positively affects the student test score in examination. Enyi, Kpurkpur, Onah, Omenka, Iorkpiligh, Igori, Eru \& Jato (2017) observed that the measurement of students' previous educational outcomes is the most important indicators of students' future academic performance. It states that, 'the higher the previous performance is, the better, and will predict the student's academic performance in future'.

Alcohol is a colorless, volatile, flammable, fermented liquid that has intoxicating constituent of wine, beer, spirits and other drinks. Alcohol is no ordinary commodity but a substance that can be depended upon. Production and consumption of alcohol in the modern Nigeria is on the increase and the volume is highly unrecorded due to illegal and local productions and the scarcity of data on the legality of production (Chikere \& Mayowa, 2011). World Health Organization (2004) ranked Nigeria among the thirty nations with the highest per capita consumption of alcohol worldwide. The new drinking norms that have evolved are drinking competitions among youths. Bar owners, brewery's representatives set out prizes for the fastest drinkers and the winner is judged based on the quantity consumed (Odejide et al, 1987, 1999, 2006, as cited by Idoko et al., 2015). Currently, Nigeria is ranked $27^{\text {th }}$ globally in alcohol consumption, making it one of the leading African countries in alcohol consumption. It has been reported that alcohol is the most common used substance in Nigeria characterized by heavy drinking (Opeyemi, Mojisade and Oladimeji, 2019).

In Nigeria there is star trek, gulder ultimate search and a host of others. In the universities there is a group known as kegite club which uses palm wine as holy water. Heavy drinking by students can lead to positive blood alcohol levels the next day, affecting their academic programmes or class. Sleeping off after a buzz is a common practice, it can interfere with the sleep cycle, resulting in an increase in anxiety, jumpiness, irrational talks and irritability, and fatigue the day after that. Although most people take for granted that alcohol impairs memory of events that occur during intoxication, alcohol consumption has far reaching effects on 
memory and learning ability. Alcohol abuse can affect the biological development of young people as well as their academic performance and behaviour. Serious alcohol use among youth has significant neurological consequences. Alcohol damages areas of the brain responsible for learning and memory, verbal skills and visual-spatial cognition. Diagnosticians often find that these skills in adolescents who abuse alcohol are deficient in comparison to those who abuse alcohol. Scientists know that alcohol problems are tied to lower grades, poor attendance and increased dropout rates. Youths engage in alcohol use to help them cope with academic stress, negative emotions and make them look mature. Students that use alcohol as a coping mechanism tend to indulge more always in the use of alcohol and most of the time apply defence mechanism by engaging in denial and rationalization (Idoko et al., 2015). Almost one third of school students admit to having missed a class, and failing a test/examination because of alcohol (school Daze, 2000).

According to Mamman, Ahmad, and Lim (2014), 'Alcohol abuse appears to be common among males with 94.2 percent than females 5.8 percent, and the age of first use is 10 to 29 years'. It is also observed that drinking of palm wine and locally brewed alcohol such as "ogogoro", "burukutu" as well as chewing of different stimulating plants and their products is common in Nigeria.

\section{Statement of the Problem}

Great numbers of school age youths are roaming the streets of Jalingo with mental problems, indulge in rape, murder, theft, armed robbery, thuggery, dropping out of schools, wallowing in hospital wards, convicted and incarcerated in prison custody as a result of substance abuse. The menace of substance abuse has eaten deep into the fabrics of our society with no effective control measure especially in our secondary schools to tackle the problem headlong. The need to invest in preventive strategies is therefore needed, rather than the prevailing curative approaches which impacts are hardly felt. In addition, data on the trends of alcohol abuse and outcomes of poor academic performance among secondary school students remain largely undocumented in Jalingo Education zone, Taraba State, Nigeria. There is therefore need to seek more dynamic approach to combating this problem that seems to have damaged individuals especially in senior secondary schools in Jalingo Education Zone, Taraba State, Nigeria.

\section{Purpose of the Study}

The purpose of this study is to assess the impact of alcohol abuse on academic performance of senior secondary school students in Jalingo Education zone, Taraba State, Nigeria. The specific objective of the study is to:

- Determine the impact of alcohol abuse by senior secondary school students on their academic performance in Jalingo Education zone, Taraba State, Nigeria. 


\section{Research Question}

One research question was formulated to guide the study:

- What impact does alcohol abuse have on academic performance of senior secondary school students in Jalingo Education zone, Taraba State, Nigeria?

\section{Hypothesis}

One null hypothesis was tested for generalization of findings at 0.05 alpha level of significance:

- There is no significant impact of alcohol substance abuse on academic performance among senior secondary school students in Jalingo Education Zone, Taraba State, Nigeria.

\section{Methodology}

The research design adopted for this study is descriptive survey research design. Descriptive survey design collects information about a defined situation and condition or environment and the people (Okogun, 2016).

The population of this study comprised of all the SSII students of 2019/ 2020 academic session in Jalingo Education Zone of Taraba State which has 47 senior secondary schools with a total enrolment of four thousand, five hundred and ninety-four students (TSPPMB, 2019/2020). This study is limited to SSII students because they are the most current set of students on ground and they form the most stable class suitable for the purpose of the study.

The sample size for this study is three hundred and sixty-eight. Multi-stage sampling was used to select the sample size for the study using the Taro Yamane's (1976) formula for determining sample size.

The main instrument for this study is questionnaire titled: Impact of Alcohol Abuse on Academic Performance among Senior Secondary School Students Questionnaire tagged [IAAAPSSSSQ]. A pilot study was carried out on 40 male and female students at Government Day Secondary School Nukkai. The pilot study yielded a Cronbach alpha coefficient index of 0.705 . This shows that the instrument is reliable. Inferential statistics of Chi-square was used to test the hypothesis at 0.05 level of significance. Descriptive statistics of mean and standard deviation was used in answering the research questions using the SPSS package.

\section{DATA ANALYSIS, RESULTS AND DISCUSSIONS}

\section{Data Presentation, Analysis and Interpretation}

The data collected for the study were presented and analysed using mean and standard deviation to answer the research question. 


\section{Research Question}

What impact does alcohol substance abuse have on academic performance of senior secondary school students in Jalingo Education Zone, Taraba State, Nigeria?

\section{Table 1}

Means and standard deviations on alcohol substance abuse on academic performance of senior secondary school students in Jalingo Education Zone, Taraba State, Nigeria.

\begin{tabular}{|c|c|c|c|c|c|c|c|c|}
\hline $\mathbf{S} / \mathbf{N}$ & Statement & SA & $\mathbf{A}$ & D & SD & MEAN & SD & $\begin{array}{l}\text { DECISI } \\
\text { ON }\end{array}$ \\
\hline & $\begin{array}{l}\text { Alcohol abuse is an impediment to } \\
\text { student performance. }\end{array}$ & 243 & 85 & 19 & 19 & 3.51 & 0.82 & $\mathrm{HI}$ \\
\hline & $\begin{array}{l}\text { Students who abuse alcohol perform } \\
\text { better than their counterpart. }\end{array}$ & 53 & 44 & 86 & 183 & 3.09 & 1.09 & $\mathrm{HI}$ \\
\hline & $\begin{array}{l}\text { Students who abuse alcohol fail } \\
\text { Continuous Assessment. }\end{array}$ & 172 & 100 & 48 & 46 & 3.09 & 1.05 & $\mathrm{HI}$ \\
\hline & $\begin{array}{l}\text { Students who abuse alcohol often fail } \\
\text { their examination. }\end{array}$ & 186 & 104 & 26 & 50 & 3.16 & 1.05 & $\mathrm{HI}$ \\
\hline & $\begin{array}{l}\text { Alcohol abusers experience class } \\
\text { demotion. }\end{array}$ & 174 & 123 & 32 & 37 & 3.19 & 0.97 & HI \\
\hline & $\begin{array}{l}\text { Alcohol makes students often perform } \\
\text { poorly in academic activities. }\end{array}$ & 201 & 106 & 17 & 42 & 3.27 & 0.99 & $\mathrm{HI}$ \\
\hline & $\begin{array}{l}\text { Alcohol makes students easily involve in } \\
\text { examination malpractice. }\end{array}$ & 210 & 102 & 28 & 26 & 3.36 & 0.90 & $\mathrm{HI}$ \\
\hline 8. & $\begin{array}{l}\text { Alcohol abusers are those with least } \\
\text { grade. }\end{array}$ & 166 & 119 & 49 & 32 & 3.14 & 0.96 & HI \\
\hline & $\begin{array}{l}\text { The effect of alcohol abuse is only within } \\
\text { internal examination. }\end{array}$ & 67 & 78 & 101 & 120 & 2.25 & 1.10 & NI \\
\hline 10 & $\begin{array}{l}\text { Students that abuse alcohol do not study } \\
\text { for test, assignment and exam. }\end{array}$ & 165 & 126 & 26 & 49 & 3.11 & 1.02 & $\mathrm{HI}$ \\
\hline Grand & d Mean & & & & & & & HI \\
\hline
\end{tabular}

Source: Researcher's Field Survey 2019.

Results in table 1 show that all the items have the mean rating scales above the benchmark of 2.50 except the mean of item no 9 which states that: "The impact of alcohol abuse is only felt within internal examination". This shows that alcohol substance abuse has negative impact on academic performance of senior secondary school students in Jalingo Education Zone, Taraba State, Nigeria.

\section{Hypothesis Testing}

The main statistics used for analysing this study is the chi-square. 


\section{Hypothesis}

There is no significant impact of alcohol substance abuse on academic performance of senior secondary school students in Jalingo Education Zone, Taraba State.

\section{Table 2}

Chi-square Test of impact of alcohol substance abuse on academic performance of senior secondary school students in Jalingo Education Zone, Taraba State.

\begin{tabular}{llll}
\hline & Value & Df & $\begin{array}{l}\text { Asymp. Sig. } \\
\text { (2-sided) }\end{array}$ \\
\hline Pearson Chi-Square & $6.0382^{\mathrm{a}}$ & 195 & .000 \\
Likelihood Ratio & 302.323 & 195 & .000 \\
$\begin{array}{l}\text { Linear-by-Linear } \\
\text { Association }\end{array}$ & 86.025 & 1 & .000 \\
N of Valid Cases & 366 & & \\
\hline
\end{tabular}

Table 2 presents chi-square at 195 degree of freedom $\left(x^{2}=6.038, p=.000\right)$, this signifies that there is statistically significant impact of alcohol substance abuse on students' academic performance in Jalingo Education zone. Thus, null hypothesis that says, alcohol substance abuse has no significant impact on students' academic performance is hereby rejected. It means that there is a negative impact of alcohol on students' academic performance in Jalingo Education Zone.

\section{Discussion of Findings}

Mean and standard deviation were used to answer the research question on the independent variable. However the inferential statistics of chi-square was used for the analysis of the hypothesis on the Impact of Alcohol Abuse on Academic Performance of Senior Secondary School Students in Jalingo Education Zone, Taraba State, Nigeria.

The mean and standard deviation scores rating items on the impact of alcohol substance abuse on academic performance of senior secondary school students in Jalingo Education Zone, Taraba State, Nigeria, is significant. Result revealed that item 1 which states "Alcohol abuse is an impediment to student academic performance" has the highest mean rating of 3.51 and 0.82 standard deviation as perceived by the respondents followed by item 7 "Alcohol makes students easily involve in examination malpractice" with a mean rating of 3.36 and 0.90 standard deviation. Item 6 is $3^{\text {rd }}$ with a mean rate of 3.27 and 0.90 standard deviation while "Alcohol abusers experience class demotion is $4^{\text {th }}$ having 3.19 mean score and 0.97 standard deviation. Result also showed that "Students who abuse alcohol often fail their examination came $5^{\text {th }}$ having 3.16 mean score and 1.05 standard deviation. Similarly, respondents believed item 8 which states "alcohol abusers are those with least grade" has a negative impact on students' academic performance with the mean average of 3.14 and 0.96 
standard deviation. In a related development, "students that abuse alcohol do not study for test, assignment and exams" is believed to make negative impact on students' academic performance as indicated by the mean rating of 3.11 and 1.02 standard deviation. The respondents perceived items $2 \& 3$ have equal high impact on academic performance of students with the mean scores of 3.09 each and 1.09, 1.05 standard deviation respectively. However, it was perceived that item 9 which states "the effect of alcohol abuse is only within internal examination" has no impact on students' academic performance revealing a mean score of 2.25 and standard deviation 1.10 .

All the items have mean rating score above the average mean including grand mean, the grand mean for the ten items which is 3.12 is above criterion mean which indicate that the respondents perceived that alcohol substance abuse has impact on academic performance of senior secondary school students in Jalingo Education. Similarly, chi-square at 195 degree of freedom $\left(\mathrm{x}^{2}=6.038, \mathrm{p}=.000\right)$, this signifies that there is statistically significant impact of alcohol abuse on students' academic performance.

The result is in agreement with the study of Enyi (2017), on the Effect of Alcohol Consumption on Academic Performance of Students in Tertiary Institutions, College of Education, Oju, Benue State, Nigeria. Findings of the study revealed it is generally agreed that alcohol consumption among students can lead to serious health issues and even influence their academic performance. From the result of the analysis, it is therefore concluded that alcohol consumption among students can cause health issues, temporal memory loss, liver diseases, kidney failure, high blood pressure, other diseases and eventually, poor academic performance.

The present study supports the findings of Idoko (2015) who investigated the Effect of Alcoholism on Students' Academic Performance in Delta State University, Nigeria. The findings divulged that 24 participants representing 12\% were 100 level students, 28 participants (14\% ) were 200 level, $41 \%$ were 300 level students, 42 participants (21\%) were 400 level students, 2 (12\%) were 500 level students. Their CGPA indicated that 56 participants (28\%) have CGPA of 1.00-2.49, 94 (47\%) have CGPA of 2.50-3.49, $12 \%$ have CGPA of 3.50-4.49 and 26 participants (13\%) have CGPA of 4.50-5.00. Students who consume alcohol are 170 participants (85\%), 30 participants (15\%) do not. 112 participants $(66 \%)$ missed class/failed test due to hang over while 58 (34\%) denied missing test due to hang over. Nevertheless, the findings are in agreement with the work of Okagua (2015), who carried out a study on Prevalence of Alcohol Consumption among Secondary School Students in Port Harcourt Nigeria. His Results shows that, academic grades showed an inverse relationship with consumption of alcohol. Majority of those who drank alcohol (42.6\%) were experimenting with alcohol, though 5.4\% abuses are due to addiction. The most common problems experienced by abusers were fatigue and stupor with little or no productivity, alcohol made them behave in ways they later regretted and hurt their relationships.

\section{Recommendations Based on Findings}

Based on findings of the study, the following recommendations are made: 
(1) Policy Makers of the States should develop strong and comprehensive policies that address learning in a wide range of spheres, including the economic, political, social, cultural, technological environmental as well as laws regarding alcohol abuse.

(2)Awareness Campaigns: awareness campaign should be put in place. When students and parents become aware of the dangers and effects alcohol has on their lives, it keeps the issue alive and important. Some examples of awareness campaigns include: Posters and pamphlets, using drama, dance or song to express an idea, radio discussions and public service announcement, video presentation, slogans printed on T-shirts, containers and so on.

\section{Counselling Implications:}

To nurture a favorable policy environment, State Government should consider:

(1) Educational counselling should take place within the learning environment.

(2) Counselling unit and or clinic should be established in each of the Local Government Areas in the zone

(3) Group counselling should be encouraged.

(4) Every secondary school should have a Guidance Counsellor in order to:

4a. Assist the students to create new, more flexible arrangement that will aid persistence, through prioritization of daily activities, especially assignments, time spent on work, hobbies, family or friends and make decision how to manage the time well, as well as help students to adopt behaviours that are positive through the development of attitudes that build up self-confidence. The Counsellor will assist students to see clearly the aims, goals and ideas of learning situation and be able to know what has to be done, when to do it and how to do it. It follows up with the client to monitor the progress or attainability of the goals set in making career and occupational decision with methods of measuring knowledge and skills like inventories, questionnaire, and tests to verify or refute any claim.

4b. The Counsellor will aid in the promotion of advocacy as a tool for raising the profile of students and lifelong learning through keeping records and prepare reports related to the needs of students, which will later form baseline data for further studies. 


\section{References}

Ali, S. Haider, Z., Munir F, Khan h \& Ahmed A. (2013). "Factors Contributing to the Students' Academic Performance: A Case Study of Islamia University Sub-Campus." American Journal of Educational Research. 2013:1(8): 283-289.

Attah, A.P, Baba E. and Audu. J. S. (2016). The Effects of Drug Abuse and Addiction on Academic Performance of Students in Federal Polytechnic Idah, Kogi State Nigeria: International Journal of Democratic and Development Studies (IJDDS), Vol. 2, No 2, March, 2016. Website: http://www.rcmss.com. ISSN: 2350-224X (Online) ISSN: 2346-158X (Print)

Brown, M.O and Pela J.I (2000). Perception of Human Resources Managers on Drug Abuse Employees (A case Study of National Open University of Nigeria, Lagos Study centre). Unpublished MBA Project NOUN, Lagos.

Enyi. U.J, Kpurkpur V., Onah F. O., Omenka E. J., Iorkpiligh T. I., Igori W., Eru J. Ode, Jato, S. T. (2017). Effect of Alcohol Consumption on Student's Academic Performance in Tertiary Institution: International Journal of Science and Research Methodology, Research Article, April 2017 Vol: 6 Issue: 2

Idoko, Muyiwa and Aghoha (2015). The Effects of Alcohol Consumption on the academic Performance of Undergraduate Students: Psychology and Behavioural Sciences 2015: vol4, No.4, pp. 147-153.

Mamman, H.,Ahmad T. O andLim, H. L. (2014). Adolescent's and Drugs Abuse in Nigeria: Journal of Biology, Agriculture and Health, ISSN 2224-3208 (paper) ISSN 2225-093X (online) Vol. 4, No. 1, 2014.

Okogun (2016). Literacy in Everyday Life: Results From the2003 National Assessment of Adult Literacy (NCES 2007-480). U.S. Department of Education. Washington, DC: National Center for Education Statistics.

W.H.O. Publication (2004). The Health of Young People: A Challenge and a promise. 